\title{
Content, Context, Reflexivity and the Qualitative Research Encounter: Telling Stories in the Virtual Realm
}

\author{
by Nicola Illingworth \\ University of Stirling \\ Sociological Research Online, Volume 11, Issue 1, \\ < http://www.socresonline.org.uk/11/1/illingworth.htm/> \\ doi:10.5153/sro. 1216
}

Received: 13 Jul 2005 Accepted: 13 Jan 2006 Published: 31 Mar 2006

\begin{abstract}
The arrival of the virtual realm and computer-mediated communication (CMC) has attracted considerable interest within the discipline. However, the full potential of computer-mediated conversation as both a research resource and medium of communication within the qualitative research encounter awaits further exploration. In this paper, I discuss the dimensions of the qualitative 'tradition', the recent burgeoning interest in biographical methods shaping the research agenda and the significance of the virtual realm as a locus of communication. In so doing, I draw from my recent research exploring 15 women's accounts of their experiences of infertility and assisted reproductive procedures. Often, the qualitative encounter becomes a shared medium of trust, reciprocity and revelation. This research highlights the importance of not just making 'space' for participants voices and words but of acknowledging the significance of the context of communication itself - paying attention to 'where' and 'how' we speak is as critical as paying attention to what might be said. Participants within this study used and translated virtual text and virtual participation into a sense-making vehicle. In this respect, the virtual space offers a new dimension to the qualitative research encounter and we need to remain aware of the opportunities this affords.
\end{abstract}

\section{Keywords: Qualitative Methodology; Computer-Mediated Communication; Biographical Methods; Reflexivity}

\section{Introduction}

1.1 The arrival of the virtual realm and computer-mediated communication continues to attract considerable interest within the discipline. As Hine (2004) acknowledges in her thematic review, over the past decade commentators have explored the multi-faceted nature of the virtual realm as a topic/location (Bromberg, 1996; Jones, 1997, 1998; Schroeder, 1997; Ward, 1999; Hine, 2000, 2002), as a research resource (Coomber, 1997; Selwyn and Robson, 1998; Chen and Hinton, 1999; Jones, 1999; Ward, 1999; Mann and Stewart, 2000; Illingworth, 2001; O'Connor and Madge, 2001) and as an alternative and more imaginative way of both structuring and publishing research (Dicks and Mason, 1998; Slack, 1998).

1.2 Commentators have also acknowledged that the internet is increasingly being used as a mechanism for the delivery of social support and self-help (Pleace et al, 2000), underlining the therapeutic potential of computer-mediated conversation (Miller and Gergen, 1998). However, early consideration (Rheingold, 1994; Bromberg, 1996; Jones, 1997) of the potential of these virtual groupings to become 'virtual communities', creating a separate social space and reality from the one in which people live has been much debated (Wellman and Gulia, 1999). Likewise, the postmodern cultural analyses of cyberspace as a site of disembodied fragmentation, multiple personas and varying 'masked' presentations of the self (Turkle, 1995), accompanied by the 'illusion that there is a way of being in possession of something without being reduced to matter oneself (Vasseleu, 1997: 56), has also been questioned. As Markham (1998: 222) argues,

'... we academics who write about the transcendence of the body, the fragmentation of identity in cyberspace, the hyperreal, etc., may be making too much of the entire phenomenon ... Talking with ... users has taught me something very meaningful: People know they are not really transcending the physical world ... They might like to forget it; They might like to play with various roles and encasements and personalities ... but these users do not live under the illusion that one place is more real than the other.' 
replaced by the recognition that virtual spaces also remain constrained by the powerful structural forces of race, class and gender (Kendall, 1998). As Mann and Stewart (2000: 160) discuss, it cannot be assumed that virtual anonymity automatically fulfils its egalitarian promise. Further, Parks and Floyd (1996) argue that people do not appear to draw a sharp boundary between cyberspace and real life and, rather than considering the 'exotic' capabilities of the internet and cyberspace, attention should be turned to how people are putting it to ordinary social uses. Indeed, Hardey (2002: 571) argues, 'there is a tension between the conceptualisation of an empty free-for-all virtual social space and an approach that pays attention to the way embodied sociability anchors and shapes interactions within the virtual landscape'. By focusing too far on online settings in their own right, the opportunity to explore what happens when online is interwoven with offline social life has been overlooked - 'the majority of research about the internet has been research in the internet' (Hardey, 2002: 571). This timely reminder 'that what happens online is interwoven with offline social life and that the two are mutually shaped and shaping' (Hine, 2004: 4.5) remains central to further development in this field, reminding us that the full potential of computer-mediated conversation as both a research resource and medium of communication within the qualitative research encounter also waits to be explored. As Markham (1998: 20) notes,

'...computer-mediated communication appears to be experienced along a continuum: For some, the Internet is simply a useful communication medium, a tool; for others, cyberspace is a place to go to be with others. For still others, online communication is integral to being and is inseparable from the performance of self, both online and offline.'

1.4 The purpose of this paper is to draw on this continuum, highlighting the significance of the virtual space and the interdependency of these dimensions within the qualitative research encounter. Earlier negative understandings of CMC as an impoverished medium (Hine, 2000) have long been transcended. Replacing the notion of 'cyberspace' - a conceptualisation that presupposes an 'independent reality' (Kendall, 1999) with the idea of 'connected space', affords recognition of the fact that individuals exist online and offline simultaneously (Kendall, 1999: 60), allowing for the exploration of how participants may locate themselves within, use and blend the two. Indeed, I earlier (Illingworth, 2001) referred to CMC as a form of 'disembodied' communication. This is certainly the case when we consider the absence of researcher/participant physicality in the setting and the (not insurmountable) difficulties that may be encountered. However, my more recent research highlights $\mathrm{CMC}$ as a tool used to consider and reflect upon experiences, illustrating the virtual realm as a powerful medium of communication and reflection within the qualitative research encounter. As Louise, one of the participants, advised: 'I like to talk when my body isn't there'. While this statement may appear to support commentaries (eg Featherstone and Burrows, 1995) that celebrate the virtual realm as one unencumbered by the constraints of time, space and body, in contrast, participants used and translated virtual text and virtual participation into a sense-making medium. While 'cyberspace' may at times operate as a place to 'be' (Markham, 1998), communication within remains intimately connected to the offline social world and, within this research, became a critical component of the qualitative research encounter.

1.5 Through the following sections, I discuss the dimensions of the qualitative 'tradition', the recent burgeoning interest in biographical methods shaping the research agenda and the significance of the virtual realm as a locus of communication. In so doing, I draw from my research (Illingworth, 2003) exploring 15 women's accounts of their experiences of infertility and assisted reproductive procedures. In relation to the recent 'revival' of the body within sociology, I reflected upon the place of the female body within a now 'embodied' sociology. Throughout, I engaged with a number of methodological difficulties, developing the position that a point of access in this field begins with a move away from notions of the 'atomised individual' (Miller, 2000) towards thinking through the body and our experiences using reflexively constructed biographies (Jackson and Scott, 2001). Acknowledging the influence of both feminist and hermeneutic perspectives and situating my approach within a temporal and biographical framework, I incorporated a series of asynchronous e-mail life story interviews within the study.

1.6 Sampling decisions have been conceptually driven, reflecting the experiences of women living with and through infertility. Participants thus typify certain conceptually based types on the basis of their relevance to my research questions and analytical framework (Mason, 1994). This target group, by definition, remains representative of the phenomena of interest as opposed to the wider population. To select participants, four online support forums were identified. I posted a series of repeat calls for research participants via site bulletin boards and topic-focused discussion groups. Of the responses received, 9 participants took part in asynchronous email life-story interviews. These were conducted consecutively, with a minimum completion time of 12 days and a maximum completion time (including periods of 'absence' online) of five weeks.

1.7 Data analysis focused upon the conditions of meaning-making and understanding, emphasising the biographical and temporally-situated nature of women's embodied narratives in this field. The virtual realm remained central to these research encounters and, moving on from my earlier commentary exploring the 
ethical aspects of using the internet as a research tool alongside some of the difficulties arising from lack of physicality in the setting (Illingworth, 2001), I extend the debate further. Critically, the way the researcher and participant enter and communicate within the research field remains a vital and influential element of qualitative inquiry and research outcome (Sawakis and Tzanakis, 2004). Throughout the following discussion and analysis, I use pseudonyms to respect participant confidentiality.

\section{Qualitative research: life narratives within a virtual space}

2.1 At a fundamental level, the qualitative approach suggests human action cannot be understood without understanding the meaning that participants attribute to action - their thoughts, feelings, beliefs and assumptive worlds (Marshall and Rossman, 1998: 58). By emphasising the importance and value of context, setting and participants' frames of reference, the qualitative researcher stresses the unique strengths of this approach for searching for a deeper understanding of participants' lived experiences.

2.2 Within this broad spectrum, a number of approaches can be discerned that hold qualitative research together, each underpinned by particular philosophical assumptions that speak to a developed understanding of how knowledge can be generated. This is an enormous field and, drawing from Schwandt (2000), I seek only to provide an overview here, highlighting some significant themes.

2.3 The broadly interpretivist position ${ }^{[1]}$ suggests that it is both possible and desirable to understand the subjective meanings of action while doing so in an objective manner. By 'bracketing our experiences' and employing methods that allow the researcher or interpreter to 'step outside their various frames of references' (Schwandt, 2000: 193), an 'inside understanding' of the actors' definition of the situation may be acquired. In contrast, and from a hermeneutic position, 'understanding' is interpretation and precisely the very condition of being human. Thus, it cannot be subjected to procedure or approached as a rule-governed undertaking. If it is possible to 'step outside of ourselves' in the pursuit of understanding, then this also implies that once the shackles of tradition have been shaken off, the 'truth' simply waits to be revealed. Essentially, from a hermeneutic position, meaning is participative and thus cannot be reproduced by the interpreter (Schwandt, 2000: 194). The point is not to reveal the truth (which surely cannot exist) but to engage with the effects of tradition in a dialogical encounter with what is not (already) understood and clarify the conditions in which understanding may take place and emerge (Schwandt, 2000: 195; 207).

2.4 Sharing an affinity with the philosophical hermeneutic approach, a (loosely) social constructionist position affirms that nothing exists independently of our construction of it. Yet this does not suggest that 'knowing' is a passive procedure whereby data and information is simply imprinted on the mind. Rather, as human beings, we do not 'find' knowledge - we make it and make sense of it. Likewise, 'we do not create meaning. We construct meaning. We have something to work with ... As Heidegger and Merleau-Ponty repeatedly state, the world is 'always already there' (Crotty, 1998: 44).

2.5 Similar to the discussion of the effect of 'tradition' within the hermeneutic position, a broadly constructionist approach argues that there can be no unmediated grasp of the social world that exists independently of the interpreter and that all claims to knowledge take place within a particular conceptual framework. However, while both positions share an affinity with the notion of a 'coming into being of meaning', the similarity ends here. Philosophical hermeneutics trusts in the potential of language and interpretive practice to disclose meaning (emerging within the dialogic encounter) and thus enables the exploration of being (Schwandt, 2000: 198). It is this position that offers new possibilities within the virtual arena.

2.6 Reflecting wider concerns concerning how we enter the research field and communicate participants experiences, Chase (1995), in a critique of conventional sociological interviewing and the suppression of participants' stories, advocates the importance of making space for interviewees to frame their experiences in their own terms. 'Making space' within my recent research centred upon the use of life and personal narratives within the virtual realm, reflecting the recent burgeoning interest in biographical methods.

Combined with a concern to link macro and micro levels of analysis (Chamberlayne et al, 2000) this reflects a wider shift in thinking currently shaping the research agenda and one offering new opportunities within the virtual arena. Through life narratives and stories, 'we come into contact with our participants as people engaged in the process of interpreting themselves' (Lieblich and Josselson, 1995: ix). My research exploring infertility characterises women's experiences as both transformative and interactive, where issues of time, space and control remain central. Underlining critical longitudinal components within women's stories and focusing on identified 'turning points' as experiences unfold, this position bears some relation to Schutz's (1970) notion that participants possess a stock of knowledge that is simultaneously substantive, reflexive and emergent.

2.7 Acknowledging my hermeneutically-influenced position, understanding experience takes place through the dialogic encounter over time, as part of the interpretive act itself and as part of the ongoing development 
of participants viewpoints during the telling of their experiences - how we 'know' is both an emergent process and one caught up in a 'web of intimate social relations' (Mauthner, 2002: 32). As Becker (1997) persuasively argues, those suffering 'disrupted lives' create meaning through story-telling. This also echoes Atkinson's (1998: 7) sentiment that 'we become fully aware, fully conscious of our own lives through the process of putting them together in story form ... Telling our story enables us to be heard, recognised and acknowledged by others.' Further, computer-mediated communication offered a new space and dimension for the telling of these stories. Often, the qualitative encounter becomes a shared medium of trust, reciprocity and revelation. However, using the virtual realm as a research site highlighted the importance of not just making 'space' for participants voices and words but of acknowledging the significance of the context of communication itself - paying attention to 'where' and 'how' we speak is as critical as paying attention to what might be said. As Diane reveals:

'The advantages of doing this online is that you're perhaps more honest and forthright than you would be when speaking to someone. Sometimes when you talk it's more difficult - you can usually see who you are talking to and you modify what you are saying by their reactions - it's much easier to type something emotional than dredge it up and articulate it quite so well. If we were speaking directly would I modify what I was saying to how you reacted? I think I might.'

2.8 The data I use here, collected using asynchronous e-mail life-story interviews, reflect narratives of transition and interpretation as participants explored and made sense of their experiences. As Widdershoven (1993: 19) states, the intertwining of experience and story lies at the heart of both individual life and understanding. Critically, online communication remained intertwined with women's stories throughout, offering, as Markham (1998: 125 original emphasis) suggests, a medium experienced 'along a continuum from tool to place to way of being' .

2.9 However, Markham (1998: 124-126) also identifies the text-based nature of online communication as a limitation, both via the inability to see faces, to hear the meaningful sounds that accompany words and via the extent to which users control this communication medium:

'For many users, examining and editing their words before they "utter" them gives them the feeling that they have control over their presentation of self as well as control over the other's perceptions of the self ... A crucial feature of online communication media is that users can limit the extent to which others can view or touch them, physically and, presumably, psychologically ...control can be directed inward ... or control can extend outward from the self to put restrains on the Other' (Markham, 1998: 124)

As I have previously noted (Illingworth, 2001), the lack of physicality and reliance on the written word can cause difficulty. For example, Diane repeated her concerns throughout our discussions, often returning to and clarifying earlier points made: 'Has that come across the right way? Sometimes I wonder if what I'm writing is coming across as what I mean!' This process of questioning and continuing reflection may also remain part of the face-to-face qualitative encounter. However, the text-based, temporal and spatial nature of virtual communication offers new dimensions, underlining Mann and Stewart's (2000: 95) suggestion that,

'The ability of the computer to reflect a person back to themselves opens up the possibility that for some individuals, computer mediated communication ... may be an ideal method to generate rich data about the subjective self, a self accessed in what may be experienced as an almost transparent process of relating to one's own consciousness.'

2.10 CMC offers a new and critical component to long-standing debate - the 'oral-writing dichotomy' (Mann and Stewart, 2000: 182) - about the quality of data that can be collected using face-to-face as opposed to written materials. Within the written text, Good (1996: 82) argues communication may be impoverished in terms of its social and emotional content and spontaneity is lost, reducing the prospects for negotiating meaning. However, CMC has the capacity to bridge this dichotomy, combining the characteristics of both oral and written communication, presenting 'writing that very often reads as if it were being spoken - that is, as if the sender were writing talking' (Davis and Brewer, 1997: 2). In the case of my earlier research (Illingworth, 2001), the virtual realm opened the door to a previously hidden and 'silent' world of experience, illuminating a general awareness that people may be more willing to interface with a computer screen than talk directly, feel less inhibited by the evaluation of others and appear more aware of their private selves online (Matheson, 1992; Jones, 1997). However, while I refrain from suggesting that the virtual realm can be considered as a research setting and resource par excellence, the virtual combination of both oral and written communication reveals an alternative space where we can explore how 'we write what we think we know' (Markham, 1998: 20). As Pearl, one of the participants in this study, narrates: 'Thanks for letting me talk all this through and getting all this off my chest. I hadn't realised just how much I hadn't really dealt with. As the advert said, 'It's good to talk!' 
2.11 Bourdieu (1977: 1-30) argues we must both scrutinise the relationship between our methodology and the information it has enabled us to collect and also consider how this may determine the eventual form of our accounts. As commentators (Anderson and Jack, 1991; Collins 1998) suggest, this entails paying more attention to process than product. What cannot be said in one moment may become clear, and emerge, over time, underlining the importance of the research encounter and interaction between researcher and participant, the dialogic process within and the context of communication itself. Through the remaining sections, I discuss my analytic strategy and illustrate participant's narratives moving through the research encounter. In so doing, I illuminate not solitary instances or momentary thought but developing understanding as it occurs.

\section{Analysing virtual narratives: a relational ontology}

3.1 As I have discussed, how the researcher enters the field of enquiry, the context of communication and analytical strategy remains critical to final outcomes. My analytical strategy equated with my narrative and hermeneutic approach to data collection, embracing both the temporal and contextual dimensions of experience in this field. Influenced by Mauthner and Doucet's (1998) adaptation of the voice-centred relational method, Rosenthal's (1993) method of objective-hermeneutic case reconstruction and Coffey and Atkinson's (1996) emphasis on the exploration of narrative chronicle alongside narrative context, form and function, this strategy focused on the process of meaning-making within research participation itself. This can be best described as a layered strategy and one continually moving back and forth through the concrete and substantive details of the data, the minutia of the narratives, to some more general analytic themes as I moved through a series of readings (Mauthner and Doucet, 1998). The advantage of this approach is in becoming increasingly tuned to the individual case, listening for and noting issues, voices and accounts of negotiation and transition as women recounted or moved through their experiences of infertility. Each subsequent interview and reading continued this focus on tracing, confirming or expanding issues and voices both within and across narrative transcripts. Recognising time as a negotiated, experiential and analytical tool, narrative analysis focused on three interrelated dimensions. Firstly, an individual dimension, laying emphasis on the subjective interpretation and reflection upon events and experiences detailed. Secondly, a temporal dimension, highlighting the analysis of life story narratives and issues arising within a temporal lens. Finally, a contextual and relational dimension, acknowledging Collins' (1998: 3.10) observation that interviews often involved 'a stream of narrative, involving an intricate braiding of stories. Interviewees, in telling stories about themselves in relation to others, reconstitute themselves'. Laying emphasis on the subjective interpretation of infertility as a 'turning point' (Charmaz, 1994) within the life story, the sections below illuminate first the significance of the virtual realm as a locus of communication and interaction within this field; secondly, I illustrate the process of meaning-making developing both through the narration of and reflection upon the life story interview. The sometime prolonged periods of participant absence, reflection and re-statement during the course of the interviews underlines the conceptualisation of the life story interview as an interactional process (Miller, 2000), a shared encounter where stories are negotiated during social interaction and through time. Again, this is aided by asynchronous computer-mediated discussion, allowing time for both distance and reflection and, critically, time to talk and time not to talk.

\section{First encounters and 'being there'}

4.1 As Markham (1998: 87) contends, 'people experience cyberspace as they experience life ... All life experiences can be more meaningful at certain times than at other times'. Nobody lives 'only' in cyberspace (Kendall, 1999: 70). However, this form of communication interaction provided participants with a 'safe space to think things through where I didn't have to worry about saying the wrong thing ' (Kate). During the early stages of research participation, many stories are first characterised by the desire for secrecy, reluctance to talk to others and consequent isolation. Early commentary confirmed virtual interaction as a meaningful and, at times, therapeutic medium offering 'respite from being so alone with all of this' (Janet). As Kate adds:

I prefer cyber-support, with others that really know how you feel as they have been there themselves. I've tried one-to-one at the hospital but this just seems to bring things to the surface but didn't help me think about it and deal with it afterwards.'

4.2 More recent commentaries have acknowledged the potential therapeutic components of the qualitative research encounter (Kvale, 1996) and the need to explore therapeutic impact within (Birch and Miller, 2000; Colbourne and Sque, 2005). Within this research, many participants welcomed the chance to participate and share their experiences using this medium. This eagerness may, in part, reflect the specific nature of their experiences - infertility remains a sensitive and socially isolating experience. As in O'Connor and Madge's (2001) study, participants perceived the virtual medium as an 'anonymous, safe and nonthreatening environment' (2001: 11.2). However, as I have suggested, the virtual realm also offers a new 
dimension to the qualitative research encounter. While I do not suggest online as opposed to FTF communication is any more meaningful per se, within this research encounter virtual communication offered a mode of being and communication that diluted the tensions, restrictions and expectations of the offline world. ${ }^{[2]}$ In this study, participants recognise living without children as a socially isolating experience alleviated by participation in the virtual realm:

Lisa: Offline, you tend to find that your interests and what you talk about is different from your other friends ...When I am feeling down, or need a pick me up or just ask 'why me?'I feel these online groups help and I don't feel so isolated.

4.3 While Goffman (1969; 1983) underlines how we negotiate shared 'vocabularies of bodily idiom' central to the presentation of the self within the face-to-face interaction order, it is precisely the lack of face-to-face interaction that remains central to the freedom of emotional expression described by participants, as Paula and Diane discuss:

Paula: The advantage of talking with people online is that we don't really know one another so we are allowed a certain degree of freedom of expression that might get filtered if they were "real life" friends. I don't feel I have to holdback.

Diane: I think too that the thought of going into an actual support setting is daunting. You don't know anyone, everyone looks at you when you come through the door and you feel compelled to say something. Online you can lurk around until you feel comfortable, no one has to know you are there. You can talk when you need to and not once a month on a Tuesday evening. It's private, both from the anonymity point of view, but it's also in your own home.

4.4 Rather than using the virtual as a means of 'escaping' the embodied self (Hardey, 2002: 570), participants embraced the virtual realm both as a practical information resource and as a medium of communication allowing a greater degree of reflection and one influenced by the perceived anonymity of this medium:

Kate: Sometimes things are better left unsaid on the outside. Doing it here you get the release without the fallout ...I think it also helps that you can switch off the computer and what you've written disappears.

Diane continues,

'It gives you additional time to think and you can take on board other peoples comments. Infertility is a rollercoaster and you don't always know what the highs and lows are going to be. Sometimes someone will talk and make sense of something that's been puzzling me and I need time to absorb it and think. Even a one minute delay would not happen in conversation, but you can sit in front of a keyboard, think and then type what you mean to say, not the first thing that comes to mind.'

The researcher, the participant and the research encounter: reciprocity, reflexivity and meaningmaking

5.1 In the section above, I have illustrated the significance of the virtual as a locus of communication and cyber-support in this field. Jones (1997: 15) argues the internet, or cyberspace, represents a narrative space that contends for our imagination. CMC and offers a new space as a sense-making medium within the qualitative research encounter. Many participants had yet to fully make sense of their experiences. Irrespective of treatment success or failure, the experience of infertility acted as a major disruptor to their lives leaving, in many cases,

Paula: 'nothing left but a sense of limbo and no control over what can happen next. Even though we were successful I STILL FEEL INFERTILE. I want to moan about my lot but because of all the treatment and all the effort put in, I don't feel able.'

As Karen, reflecting on research participation, observes,

'The main advantage of this is that I can say what I like! You don't know me so won't make a judgment. It's good to offload. Where I am is too difficult to talk about with friends. I don't like them to think that I am obsessed with this or that I am off the rails :(. Ha! Sometimes I don't even think about it with myself :)'

5.2 Similarly, Orgad (2005) explores the proliferation of breast cancer forums as part of the broader 
phenomenon of the use of the internet for health-related purposes and the possibilities offered by computermediated communication. Anonymity and disembodiment remained pivotal elements to the disclosure of women's stories online. Using the medium, participants gained a sense of control over the content of the representation of their experiences, producing their own constructions and deciding where, when and how they would appear (Orgad, 2005: 5). As I retraced participants' stories, I became increasingly aware of a number of levels to participants' voices, each narrating differing, yet interrelated, layers of understanding and experience. Firstly, the 'expectant voice' reflecting participants' recounting their self-expectation during the period prior to infertility and a picture composed primarily of perceived cultural norms, values and the expectations of others. Secondly, the 'experiential voice' reflecting participants' recollection of the treatment period in relation to these expectations. Finally, the 'meaning' voice, illustrating a process of reconciliation in the spaces between the experience, recollection, reflection and research encounter. By focusing my attention on the way participants spoke about themselves within a temporal framework and following the use of the active 'l' (Coffey and Atkinson, 1996) within the narration, a change in voice can be identified as participants described their early expectations in relation to future parenthood, the recollection of the experience of infertility and the final resolution of this experience. This change is illustrated by a move from participant narration characterised first by the use of terms reflecting wider social and cultural expectations in relation to parenthood: Karen: 'It was something I always thought would happen. I expected it. It was the next thing to do after settling down' and Pearl continues: 'It was expected. They all kept asking 'when' and they kept reminding me I was 'getting on' for it.'Through the process of the interviews, participant narratives begin to revisit and challenge past assumptions and expectations. Participants voice a sometimes gradual change and developing awareness, illustrating the process of active negotiation between previously held expectations and assumptions and the challenge of reflecting on their experiences. This is underlined by the use of the more reflexive and personal 'l' within participant narratives. This medium of communication, alongside the practical ability to save a transcript of each interview interaction remained central to this process, for example:

Dorothy: 'It's good reading this back. Makes me think just how much we are brought up in an era where fertility is promoted as "controlled"... Lasting effects? The draw backs have been all the things I think about now. You can't forever wipe out a number of years of your life and pretend they didn't happen."

Pearl: 'I've been reading this over. Surprised that things surfaced I hadn't expected. Didn't think I would have so much to talk about! This is helping me in a funny kind of way. I like to share my thoughts and I can read them too.'

Kate: 'Doing this helps a lot ...I can work out how I feel and present a more balanced face to the world ... getting it out of my head and onto paper has always been good for me. I know you're reading it at the other end but the anonymity of email is so powerful.'

5.3 Critically, CMC provided not only a space to talk but also offered both a space to reflect and a space not to talk. Often, interviews were characterised by periods of silence, at first disconcerting for the researcher keen to maintain interaction and contact. While this may also characterise a FTF interview, I had to resist the temptation to exploit the virtual medium by overly-prompting participants to respond to my questions. The experience of infertility was perceived as a controlling situation by participants - a sense of control that was experienced long after treatment ended. At times, interview narratives reveal detailed self-appraisal in relation to others. For example, the difficulties of dealing with family expectation, work pressures, friends, social events and pregnancy encounters. At times the research encounter itself become part of participants attempts to regain control over their stories, experiences and life directions. The interview both interrupted and disrupted established sense-making mechanisms used by many women to 'bracket' their experiences from their everyday lives. Difficulty both relating and dealing with these issues resulted in, for some participants, temporary withdrawal from the research interview.

Karen: Sorry my replies not so frequent at the moment. Feeling weight on my shoulders that
just never goes away. Busy with work. Being in control. I've allowed this to control us. But
these past few days I've been saying to my hubby. We have got to get on with our lives so
we are booking leave and making plans. So from now on at least for a while I am in control.
I need to stop thinking to do this so l'll break for a few days? Hope that's ok?

5.4 For Jayne, withdrawal was less explicit. Early on, Jayne forwarded frequent and lengthy replies to questions asked and continuing discussions. However, as the interview progressed, the time between each contact increased:

Sorry I haven't been on the internet for a while. Thought l'd grab a few minutes while the teletubbies are on. Don't know how long I'll get ... How far am I behind? I know I haven't replied as often but some of this I haven't thought about for so long.' 
5.5 During feedback discussion Jayne advised that while she was happy to continue with the interview and at times found it therapeutic, she was still 'struggling a bit dealing with some of these skeletons in the cupboard'. Similarly, many narratives reflected difficulty both recollecting and making sense of sometimes harrowing experiences. On numerous occasions, I sat in front of my screen waiting for the familiar sound of a message arriving in my inbox. Normally, replies were frequent but on occasions, I waited for two, three days, sometimes a week. This could be the result of practical difficulties such as forgotten events, visits, trips away, job/family pressures and commitments or technological difficulties. Yet at other times, participants would resume contact advising 'This took some thinking' (Paula) or 'I wasn't really sure if this was an issue for me but ...'(Kate). Mann and Stewart (1999: 143) argue absence or non-response in the virtual venue can be deeply unsettling for both interviewers and participants, potentially undermining a developing sense or 'rapport'. However, within this project, 'absence' or the lack of communication was as much part of the research encounter as the narrative itself.

5.6 A sense of a lack of control over life direction remained central to all narratives, irrespective of treatment success or failure. This 'loss of control' is described in relation to diagnosis, the beginnings of subsequent treatment and challenge to early assumptions. This is perceived at two levels. Firstly, the lack of personal control over the treatment regime and secondly, the related lack of control or uncertainty over life direction and future planning. Many participants had attempted to regain or maintain control by 'bracketing' or setting apart their experiences from the flow of their everyday lives. Yet at times, unexpected episodes, encounters and experiences, including research participation, reawaken this uncertainty. The effect of disrupting this mechanism through the research encounter is illustrated above by the occasional and sometimes prolonged withdrawal from the interview itself as participants reflect further on their experiences. However, at times this disruption is also evident within the narrative itself. As Elaine describes,

'I had a meeting with the Consultant when we started again. He asked what drugs dose l'd been on ... he looked shocked when I didn't know ... they thought I was barking ... I guess this is further evidence of my overall attempt at "denial". Part of me thinks it is unhealthy to dwell on it/analyse it too much, part of me thinks it is unhealthy to ignore/deny it. Can't win at the moment. Writing it here is tough sometimes."

5.7 On another occasion, Louise advised, 'Yesterday was such a crap day I couldn't bring myself to think about it.' Louise moves on to reflect on the days events, a process leading to more developed reflection concerning past failure and hopes and fears for the future. Louise ends our scheduled interaction advising, 'Sorry, can't do anymore tonight. Feel incredibly sad'. As Collins (1998: 3.22) rightly points out, the interview is a highly complex social interaction and it is 'a gross oversimplification to assume that the interviewer merely asks and the interviewee merely answers questions'. In this research, narratives about the process of interviewing became part of the interview itself. Adapted to the virtual setting, the life story interview critically became a medium of both engagement and disengagement as participants filled out their stories.

5.8 Thus far, I have made an illustrative decision to give primacy to participants' voices. This might suggest the power of my own voice is more noticeable by its very absence. However, I embraced this approach not to solve the problems of understanding (which would be contrary to its central tenets) but to firstly clarify the conditions in which understanding takes place. Secondly, meaning may be uncovered but this meaning is necessarily a product of the dialogic encounter and interpretive act itself. As interviews continued, I became more than a listener - I became a commentator, participator and contributor to these stories. This again underlines the sometime 'therapeutic-ness' (Morse, 1994) of the qualitative research encounter. As Morse (1994) discusses, this 'therapeutic-ness' evolves from the participant being offered a listener, which gives them an opportunity to self-reflect, the result being greater self awareness. This also remains bound up with the issue of reciprocity within the research encounter. At times, narrative exchange entailed the mutual exchange of personal information, moving towards equalising self-exposure between researcher and participants (Ribbens, 1990). Indeed, the central thread that held this research together encouraged the renegotiation of my own personal biography through exploring others experiences in this field. This process may be described as one temporally situated on three levels: firstly, my own researcher reflections throughout the research process; secondly, participants' ongoing reflections throughout the research encounter and finally, recognition of our roles as co-producers of the narratives and stories within this research. This reflective practice impacts upon and goes some way towards equalising the power relations at times inherent in the research process and makes the researcher, as well as the researched, the focus of critical appraisal (Mauthner and Doucet, 1998). Nonetheless, I also echo Letherby's (2002: 4.5) position that 'we should not characterise respondents as uniformly passive or powerless'. During participation and through the process of reflection, participants described making sense of their experiences, making choices as to what to include in their stories, revisiting, refining and at times rewriting their stories in response to continued reflection. At times, as I have discussed, this process necessarily excluded me, as researcher. In this respect, computer-mediated communication operated as a mechanism of control for 
participants over the research encounter. Towards the end of the interviews, participants were invited to reflect further on the advantages and disadvantages of the research encounter and I include some detailed comments here:

Lina: Yes. It's been fine. It's been quite therapeutic to get it all out like this, you know? Disadvantage? Sometimes I don't want to read through it? Not sure what I'm saying here? Just a niggle.

Paula: It's gone well. The thing you've done best is re-asking questions with another nuance. That helps in answering! Sometimes I have a real problem talking it through and I can't see the wood for the trees...this journey has completely changed my self perception ...It's only through conversation and talking like this that l've come to realise this.

Dorothy: It's been convenient. Nobody can hear what I'm saying and I can talk straight away when l've been thinking, not having to wait until the next meet...Downside of all of this is never meeting but then that could be a good thing. Has it come across the right way?

Jayne: I didn't really have any expectations prior to starting the interviews as I had never done this sort of thing before. But I do have to remember to check my emails - you don't hassle for them which is good. Some of them I just don't open for a while because I'm not ready. So it suits me well - I suppose we have the advantage? Disadvantages for you must be getting replies back in dribs and drabs.

\section{Conclusion}

6.1 At the beginning of these interviews, and as a researcher using the internet as a medium of communication, I often felt challenged, unsure, dominated by feelings of dislocation and uncertainty. As interviews progressed, this uncertainty diminished as I recognised CMC being used as a tool, a place to go and a place to 'be' (Markham, 1998) to talk about experiences and share a conversation yet one also intimately connected to the offline world (Hine, 2004). End commentary is generally dominated by notions of therapy and convenience, underlining the function of the narratives and, critically, the significance of making space for talking as well as making space for silence and reflection within the research encounter. I have earlier (Illingworth, 2001) discussed many of the practical limitations and difficulties arising within the virtual research encounter. CMC does not suit every research project and I do not offer a set of prescriptives here. However, within this project, $\mathrm{CMC}$ became a rich, interactive tool used to consider and reflect upon experience, illustrating the virtual realm as a sometime powerful medium of communication and reflection within the qualitative research encounter. CMC offers more than just a degree of control by the participant over the research encounter. Within this study, the research encounter and the virtual space as the context of communication became a potent force, a site where the self was often re-constituted and re-negotiated through a process of reflection and interaction and where time to talk and time not to talk proved critical, allowing for new chapters or punctuations to emerge (Gale, 1992). In this respect, the virtual space offers a new dimension to the qualitative research encounter and we need to remain aware of the opportunities this affords. I end here with Dorothy's last interview contact:

Dorothy: Ok and thanks. Let me know how you get on with this. See ya!

\section{Notes}

${ }^{1}$ I include here phenomenological sociology, the influences of Cicourel, Garfinkel and the 'language games' of Winch and Wittgenstein.

${ }^{2}$ As part of series of initial introductory contact sessions, participants were asked to discuss levels of online participation and influencing factors.

\section{References}

ANDERSON, L and JACK, D.C. (1991) 'Learning to Listen: Interview Techniques and Analysis' in S.B. Gluck and D. Patai (editors) (1991) Women's words: the feminist practice of oral history. London: Routledge.

ATKINSON, R. (1998) The Life Story Interview. Qualitative Research Methods, Series 44, London: Sage.

BECKER, G. (1997) Disrupted Lives. Berkeley: University of California Press. 
BIRCH M and Miller T 2000 'Inviting intimacy: the interview as therapeutic opportunity' International Journal of Social Research Methodology Vol. 3, No. 3 July 12000 pp 189-202.

BOURDIEU, P. (1977) Towards a Theory of Practice. Cambridge: Cambridge University Press.

BROMBERG, H. (1996) 'Are MUD's Communities? Identity, belonging and consciousness in Virtual Worlds' in R. Shields (editor) 1996 Culture of Internet. Virtual Space, Real Histories, Living Bodies. London: Sage.

CHAMBERLAYNE, P., BORNAT, J., and WENGRAF, T. (editors) (2000) The Turn to Biographical Methods in Social Science. Comparative Issues and Examples. London: Routledge.

CHARMAZ, K (1994) 'Discoveries of the Self in Illness' in M.L. Dietz, R. Prus and W. Shaffir Doing Everyday Life. Ethnography as Human Lived Experience. Ontario: Copp Clark Longman Ltd.

CHASE, S. (1995) 'Taking Narrative Seriously: Consequences for Method and Theory in Interview Studies' in A. Lieblich, and R. Josselson, R. (editors) (1995) Interpreting Experience. The Narrative Study of Lives. Thousand Oaks, CA: Sage.

CHEN, P. and HINTON, S.M. (1999) 'Realtime Interviewing Using the World Wide Web' Sociological Research Online, Vol. 4, No. 3 < http://www. socresonline.org.uk/4/3/chen.html>

COFFEY, A and ATKINSON, P (1996) Making Sense of Qualitative Data. Complementary Research Strategies. Thousand Oaks: Sage.

COLBOURNE L and Sque M, 2005 'The culture of cancer and the therapeutic impact of qualitative research interviews' Journal of Research in Nursing Vol. 10, No 5 pp551-567.

COLLINS, P. (1998) 'Negotiating Selves: Reflections on 'Unstructured' Interviewing' Sociological Research Online, vol.3, no. $3<\mathrm{http} / / / \mathrm{www}$.socresonline.org.uk/socresonline/3/3/2.html>

COOMBER, R. (1997) 'Using the Internet for Survey Research' Sociological Research Online, vol. 2, no. 2, $<\mathrm{http}: / /$ www. socresonline.org.uk/2/2/2.html>

CROTTY, M. (1998) The foundations of social research: meaning and perspective in the research process. Thousand Oaks, CA: Sage.

DAVIS, B. and BREWER, J. (1997) Electronic Discourse. Linguistic Individuals in Virtual Spaces. New York: State University Press.

DICKS, B. and MASON, B. (1998) 'Hypermedia and Ethnography: Reflections on the Construction of a Research Approach' Sociological Research Online, Vol. 3, No. 3,

<http://www.socresonline.org.uk/3/3/dicks.html>

FEATHERSTONE, M and BURROWS, R (editors) (1995) Cyberspace, Cyberbodies, Cyberpunk: Cultures of Technological Embodiment. London: Routledge.

GALE, J. (1992) 'When Research Interviews are More Therapeutic than Therapy Interviews' The Qualitative Report Vol. 1 No. 4 <http://www.nova.edu.ssss/QR/QR1-4/gale.html>

GOFFMAN, E. (1969) The Presentation of Self in Everyday Life. Harmondsworth, Penguin.

GOFFMAN, E. (1983) 'The interaction order' American Sociological Review, 48, pp 1-17.

GOOD, D. (1996) 'Pragmatics and presence' Al and Society 10, pp309-314

HARDEY, M. (2002) 'Life beyond the screen: embodiment and identity through the internet' The Sociological Review Vol. 50 No. 4 p570-585.

HINE, C. (2000) Virtual Ethnography. London, Sage.

HINE, C. (2002) 'Cyberscience and Social Boundaries: the Implications of Laboratory Talk on the Internet' Sociological Research Online, vol. 7, no. 2 <http://www.socresonline.org.uk/7/2/hine.html>

HINE, C. (2004) 'Social Research Methods and the Internet: A Thematic Review' Sociological Research Online, vol. 9, no. 2 <http://www.socresonline.org.uk/9/2/hine.html>

ILLINGWORTH, N. (2001) 'The Internet Matters: Exploring the Use of the Internet as a Research Tool' Sociological Research Online, Vol. 6, No. 2, <http://www.socresonline.org.uk/6/2/illingworth.html> 
ILLINGWORTH, N. (2003) Gendered Embodiment and the Time of Infertility. Unpublished PhD thesis, University of Stirling, Stirling.

JACKSON, S. and SCOTT, S. (2001) 'Putting the Body's Feet on the Ground: Towards a Sociological Reconceptualisation of Gendered and Sexual Embodiment' in Backett-Milburn, K. and McKie, L. (Editors) (2001) Constructing Gendered Bodies. Basingstoke: Palgrave.

JONES, S.G. (editor) (1997) Virtual Culture: identity and communication in cybersociety. London, Sage.

JONES, S.G. (editor) (1998) Cybersociety 2.0: Revisiting Computer-Mediated Communication and Community. Thousand Oaks, CA: Sage.

JONES, S.G. (editor) (1999) Doing Internet Research. Critical Issues and Methods for Examining the Net London, Sage

KENDALL, L. (1998) 'Meaning and identity in 'Cyberspace': the performance of gender, class and race online' Symbolic Interaction, 21: 129-153

KENDALL, L. (1999) 'Recontextualising "Cyberspace”: Methodological Considerations for On-Line Research' in S. Jones (editor) (1999) Doing Internet Research. Critical Issues and Methods for Examining the Net. London: Sage.

KVALE S, 1996 An Introduction to Qualiative Research Interviewing 3rd Edition, London, Sage.

LETHERBY, G. (2002) 'Claims and Disclaimers: Knowledge, Reflexivity and Representation in Feminist Research' Sociological Research Online, Vol. 6, no. 4 <http://www.socresonline.org.uk/6/4/letherby.html>

LIEBLICH, A. and JOSSELSON, R. (editors) (1995) Interpreting Experience. The Narrative Study of Lives. Thousand Oaks, CA: Sage.

MANN, C. and STEWART, F. (2000) Internet Communication and Qualitative Research. A Handbook for Researching Online. London: Sage.

MARKHAM, A.N. (1998) Life online: researching real experience in virtual space. Walnut Creek, CA: AltaMira Press.

MARSHALL, C. and ROSSMAN, G.B. (1998) Designing Qualitative Research $3^{\text {rd }}$ Edition, London: Sage. MASON, J (1996) Qualitative Researching. London: Sage.

MATHESON, K. (1992) 'Women and Computer Technology' in M, Lea (editor) 1992 Contexts of Computer Mediated Communication London and New York: Harvester Wheatsheaf

MAUTHNER, N and DOUCET, A (1998) 'Reflections on a Voice-centred Relational Method: Analysing Maternal and Domestic Voices' in J. Ribbens and R. Edwards (editors) Feminist Dilemmas in Qualitative Research. Public Knowedge and Private Lives. London, Sage.

MAUTHNER, N. (2002) The darkest days of my life. Stories of postpartum depression. Cambridge, Mass. Harvard University Press.

MILLER, R. (2000) Researching Life Stories and Family Histories. London, Sage.

MILLER, J.K. and GERGEN, K.J. (1998) 'Life on the line: the therapeutic potentials of computer-mediated conversation' Journal of Marriage and Family Therapy , 24, pp189-202.

MORSE, J.M. (1994) Critical Issues in Qualitative Research Methods. London, Sage.

O'CONNOR, H and MADGE, C. (2001) 'Cyber-Mothers: Online Synchronous Interviewing Using Conference Software' Sociological Research Online, Vol. 5; No. 4 <http://www.socresonline.org.uk/5/4/o'connor.html>

ORGAD, S. (2005) 'The Transformative Potential of Online Communication. The case of breast cancer patients' Internet spaces' Feminist Media Studies, 5(2).

PARKS, M.R. and FLOYD, K. (1996) 'Making Friends in Cyberspace' Journal of Computer Mediated Communication, 1, 4 <http://www.ascusc.org/jcmc/>

PLEACE, N., BURROWS, R., LOADER, B., MUNCER, S. and NETTLETON, S. (2000) 'On-Line with the 
Friends of Bill W: Social Support and the Net' Sociological Research Online, vol. 5, no.2 $<$ http://www.socresonline.org.uk/5/2/pleace.html>

RHEINGOLD, H. (1994) The Virtual Community: Finding Connection in a Computerized World. London: Secker and Warburg.

RIBBENS, J. (1990) 'Interviewing - an “Unnatural Situation”?' Women's Studies International Forum, 12(6): 579-92

ROSENTHAL, G. (1993) 'Reconstruction of Life Stories: Principles of Selection in Generating Stories for Narrative Biographical Interviews' in R. Josselson and A. Lieblich (editors) The Narrative Study of Lives. Volume 1. Thousand Oaks: Sage

SAVVAKIS, M. and TZANAKIS, M. (2004) 'The Researcher, the Field and the Issue of Entry: Two Cases of Ethnographic Research Concerning Asylums in Greece' Sociological Research Online, vol. 9, no. 2, <http://www.socresonline.org.uk/9/2/sawakis.html>

SCHROEDER, R. (1997) 'Networked Worlds: Social Aspects of Multi-User Virtual Reality Technology' Sociological Research Online, vol.2, no.4 <http://www.socresonline.org.uk/2/4/5.html>

SCHUTZ, A. (1970) Alfred Schutz on Phenomenology and Social Relations: Selected Writings. London: University of Chicago Press.

SCHWANDT, T.A. (2000) 'Three Epistemological Stances for Qualitative Inquiry. Interpretivism, Hermeneutics and Social Constructionism' in N.K Denzin and Y.S Lincoln (editors) 2000 Handbook of Qualitative Research. $2^{\text {nd }}$ Edition, Thousand Oaks, CA: Sage.

SELWYN, N. and Robson, K. (1998) 'Using email as a research tool' Social Research Update, Issue 21, University of Surrey. <http://www.soc.surrey.ac.uk/sru/SRU21.html>

SLACK, R.S. (1998) 'On the Potentialities and Problems of a WWW Based Naturalistic Sociology' Sociological Research Online, Vol. 3, No. 2, <http://www.socresonline,org,.uk/3/2/slack.html>

TURKLE, S. (1995) Life on the Screen: Identity in the Age of the Internet. London, Weidenfield and Nicolson.

VASSELEU, C. 1997 'Virtual Bodies/Virtual Worlds' in D. Holmes (editor) (1997) Virtual Politics. Identity and Community in Cyberspace. London: Sage.

WARD, k.j. (1999) 'The Cyber-Ethnographic (Re) Construction of Two Feminist Online Communities' Sociological Research Online, vol.4, no.1 <http://www.socresonline.org.uk/4/1/ward.html>

WELLMAN, B. and GULIA, M. (1999) 'Virtual communities as communities: Net surfers don't ride alone' in M.A. Smith and P. Kollock (editors) Communities in Cyberspace. London: Routledge.

WIDDERSHOVEN, G.A.M. (1993) 'The Story of Life. Hermeneutic Perspectives on the Relationship Between Narrative and Life History' in R. Josselson and A. Lieblich, (editors) (1993) The Narrative Study of Lives. Volume 1. Newbury Park: Sage. 